\title{
Practice of Running Dyeing \& Weaving Weekly in the Republic of China and Dissemination of Science and Technology
}

\author{
Bochong Zhao ${ }^{1} \&$ Kehui Deng ${ }^{1}$ \\ ${ }^{1}$ College of Humanities, Donghua University, Shanghai, China \\ Correspondence: Bochong Zhao, College of Humanities, Donghua University, Shanghai, 200051, China. Tel: \\ 86-21-5183-6446. E-mail: zbc_zhao@163.com
}

Received: March 27, 2021

doi:10.5539/ass.v17n6p13
Accepted: May 25, $2021 \quad$ Online Published: May 31, 2021

URL: https://doi.org/10.5539/ass.v17n6p13

\begin{abstract}
Dyeing \& Weaving Weekly (1935-1941) is a scientific and technological periodical which has been published for a long time and has never been interrupted in the field of textile in modern China. The journal publishes a large number of the latest achievements in textile science and technology, and is an important historical material and typical case for the study of modern science and technology dissemination. Rich in content, Dyeing \& Weaving Weekly focuses on solving practical problems in the textile industry and guiding the direction of scientific research, which not only promotes the dissemination of textile science and technology but also contributes to the development of the textile industry. Therefore, from the perspective of science and technology communication and the history of newspapers and periodicals, this paper examines the practice and communication strategies of Dyeing \& Textile Weekly, in order to prove that Dyeing \& Textile Weekly has a positive impact on science and technology communication in modern China, and also provides experience reference for the development of contemporary science and technology periodicals in China, which has certain reference significance.
\end{abstract}

Keywords: Dyeing \& Weaving Weekly, scientific and technological periodicals, science and technology communication

Since the Republic of China, the development of textile industry has been regarded as an important means to revitalize the economy. At that time, textile newspapers spread all over the country and became an important part of modern scientific and technological periodicals. In the past, the academic circle mainly focused on the scientific contents of sci-tech periodicals from the fields of finance, agriculture, medicine, etc., or examined the interaction between environment and sci-tech periodicals from the historical dimension. However, there is still a large gap in the research of modern textile sci-tech periodicals. Dyeing \& Textile Weekly is typical among modern Chinese sci-tech periodicals, but the relevant investigation is very rare, and there is still no special study on the practice of running the journal and sci-tech communication (Gao, 2019). This is a pity for a comprehensive understanding of modern science and technology periodicals. For this reason, this paper takes Dyeing \& Textiles Weekly as the research object to explore the practice of running the journal and the dissemination of science and technology, so as to prove the significance of Dyeing \& Textiles Weekly to the dissemination of modern textile science and technology.

\section{Practice of Running Dyeing \& Weaving Weekly}

Dyeing \& Weaving Weekly was founded by Shanghai Machine Dyeing \& Weaving Association in Shanghai in 1935. It is an important periodical in modern textile science and technology, which is published regularly and uninterrupted (Zhu, 1941). The journal has a large circulation, 50 volumes throughout the year, issued weekly. It was stopped in 1941, with a total of 151 issues. It mainly publishes the latest academic achievements in dyeing, weaving and spinning, among which there are a large number of textile technological inventions and translated works of western textile technology. In addition, the journal also reported the operating conditions of domestic textile mills, and thought about solutions to the problems of China's textile industry. It is a pure academic journal in the field of textile, and has important historical value for newspaper research and modern science and technology dissemination.

Dyeing \& Weaving Weekly aims to promote the development of textile science and technology and hopes that 
China's textile industry will one day be on par with advanced industrial countries (Zhu, 1935). Driven by this ideal, the journal has clear restrictions and requirements on the source and quality of manuscripts. At the beginning of its establishment, Dyeing \& Weaving Weekly aimed to promote the academic development of dyeing and weaving and to promote the progress of textile industry, and its publishing directions were defined as specialized textile academic, textile enterprise management, factory investigation, hardware machinery, and dye and drug descriptions (Journal of Dyeing, Woven and Textile Weekly, 1935). This move designated the production group of Dyeing \& Textile Weekly as researchers in related fields, and made high-quality academic achievements the main content of the publication.

However, under the historical environment of modern China, the lack of scientific research personnel makes stable and high-quality manuscripts become the main basis to measure the level of modern sci-tech periodicals. Therefore, the development of Dyeing \& Textile Weekly was restricted to different degrees. On the one hand, although the textile industry is a light industry, the number of textile and dyeing experts is relatively limited. In 1930, Qian Guanyi, the founder of Textile Weekly, organized the establishment of China Textile Society, which was composed of Chinese textile experts, with 275 members at the beginning (Liu, 2017). In 1934, as the highest institution in modern China's textile industry, the Department of Textile of Nantong University had been deeply engaged for many years. Among its graduates, the total number of people engaged in textile related business or academic work was only 239 (Nantong University textile science association, 1934). In 1935, there were 89 self-operated textile factories in China. The Textile Department of Nantong University believed that each textile factory needed more than 10 scientific experts (Friends of Textile, 1935). It can be seen from the data that there is a serious shortage of textile experts in modern China's textile industry. The shortage of scientific experts parallels academic research, which is a major factor contributing to the shortage, and which also parallels academic publications. On the other hand, with limited contributions, Dyeing \& Textile Weekly still faces competition in the same industry. China's modern textile industry differs greatly from that of the West, but the profit of textile products is the highest in the industry. The huge economic benefits make the textile science research attached great importance to the Chinese scientific community. At that time, industrial schools, enterprises, factories and scientific organizations all started textile newspapers to supplement school education. According to the author's statistics, there are 191 textile newspapers and periodicals in modern times. Therefore, in the process of the establishment of the journal, the search and pursuit of high quality academic achievements and stable contribution sources have become an important measure in the practice of running the journal.

In order to expand the influence of the journal and attract scholars and experts in the industry, Dyeing \& Weaving Weekly invited Zhuchuqing, an expert in dyeing and finishing, to serve as the chief editor of the journal, and also invited Zhu Wenqi, the founder of Shanghai Machine Dyeing \& Weaving Association and an expert in dyeing and weaving, to write the publication words for it. Zhu Wenqi believes that the main sticking point of China's textile industry is that its mechanical technology and organizational management are not as good as those in the West. Therefore, he calls for the unity of the same industry to explore practical technology and management methods to improve China's textile industry (Zhu, 1935). Zhu Wenqi's move can be seen as a disguised invitation to Dyeing \& Textiles Weekly, and it can also be seen that Dyeing \& Textiles Weekly has an urgent need for contributions and articles.

Thanks to the derivative relationship between Dyeing \& Weaving Weekly and Shanghai Machine Dyeing \& Weaving Trade Association, the experts and scholars of the trade association gave great support to the journal during its publication. In order to enhance the academic value of Dyeing \& Textile Weekly, it also specially invites well-known figures in the textile and dyeing field and many scholars and experts who are immersed in the textile industry (Zun, 1936). Textile experts Wang Yunxuan, Fang Birong, Huang Xige, Fu Daosheng, Zhang Angqian and others published papers one after another, making the author structure of the journal more diversified. By 1940, a total of 242 experts and scholars had published academic papers in Dyeing \& Weaving Weekly (Journal of Dyeing \& Textile, 1941). In addition, the journal also cooperated with the Department of Dyeing and Textile Science of Nantong University, and invited students from the Department of Dyeing and Textile Science to provide long-term academic achievements on dyeing and weaving for Dyeing and Textile Weekly (Friends of Textile, 1937).

The specialty of the author group makes Dyeing \& Textile Weekly have a strong academic character, and the stable and high-quality contribution source virtually prolongs the vitality of the journal. Periodicals themselves as communication media do not have the ability to produce scientific and technological information, the essence of scientific and technological communication is the process of scientific and technological information transmission. Therefore, the communication between the communicator and the audience needs stable information production groups. In the process of running Dyeing \& Textile Weekly, it makes full use of its 
professional and academic characteristics, makes use of the supporting layout of academic research, and improves the academic level and influence of the journal through stable contribution source and the latest academic achievements.

\section{The Technology Communication Strategy of Dyeing \& Textile Weekly}

The essence of sci-tech communication is the process of sci-tech information transmission. In this process, the subjective choice of editors for sci-tech information has become the communication strategy of journals. Dyeing $\&$ Textiles Weekly also diverts and screens modern textile science and technology through its characteristic communication strategy, so as to find a suitable way for its own development.

\subsection{Emphasis on Academics and Solve Practical Problems}

Dyeing \& Textile Weekly focuses on textile science and tries to create a high-level textile science and technology journal. The academic content of the journal accounts for $60 \%-80 \%$ of the total number of articles in each issue. It mainly contains the latest academic achievements in dyeing and weaving, textile technological inventions and translations of western textile technological works. In its introduction, the journal said that the guidelines from the beginning were focused on practical technical discussions, alongside organizational management (Zhu, 1935). Emphasizing on academics, solving practical problems has become an important communication strategy of Dyeing \& Weaving Weekly.

To be specific, the academic achievements contained in Dyeing \& Textile Weekly were all made by textile and dyeing experts at that time and were authoritative in the textile field. Zhu Wenqi has published several articles in New Road of Domestic Goods, Domestic Goods and Social Class, and Domestic Fabric Dyeing Method in order to find a way out for China's textile industry from the perspectives of academic research, textile sales and manufacturing. Editor-in-Chief Zhu Chuqing also published a number of research papers on the application of electrolytic bleach, mercerizing method on wool, and new method of dyeing anilinin oxides to support the academic status of the journal. Other authors, such as Que Pingzhi, Zhang Zunshi, Shao Zhongying, Xu Yangnan and Cui Fuzhuang, were also important authors of Dyeing \& Weaving Weekly. They are all members of Shanghai Machine Dyeing and Weaving Association, as well as scientific experts or textile industrialists. Therefore, the articles published in Dyeing \& Weaving Weekly can take into account the needs of academic research and industry.

In addition, in order to seek solutions to practical problems, Dyeing \& Textile Weekly publishes a large number of the latest scientific research achievements in the textile field. Jiang Naiyong, an expert in textile science, published his magnum opus Combing, Paperback Method of Combing Machine, and General Introduction of Thrusting Machine in this journal. Wu Shikai, a printing and dyeing expert, also published many articles in the journal, among which 'synthetic rosin and its future development', 'study of phosphoric acid', 'practical dyeing', 'dye analysis' and other articles made contributions to solving the problems of printing and dyeing production technology. Du Yansun, an expert in dyeing and finishing, has been contributing articles to the journal for a long time, and his articles, such as overview of domestic textile dyes, fastening printing method of silk, and verification of dyestuff magazines, have provided new methods for modern dyeing and weaving production from the technical point of view. Huang Jianzhang, a famous textile technology and management expert, has published technical operation articles in this journal, such as 'Points for Attention on the Use of Scraper', 'Causes of Sizing Machine Flannelette Damage and Ways to Save' and management articles, such as 'How to Reform Old Weaving Mines'. Dyeing \& Weaving Weekly also serialized problems in China's textile factories during production. For example, the journal published 10 serial issues of Zhang Wulie's 'A Study on Temperature and Moisture Ventilation in Cotton Textile Factory' from 1937, Vol. 2, No. 28 to 1938, Vol. 3, No. 7 for the rainy season peculiar to the south of the Yangtze River, which scientifically processed textile production under special weather.

Dyeing \& Weaving Weekly is not only a platform to display scientific research achievements, but also a bridge for communication between the industry and academia. According to the author's statistics, the journal from 1935 to 1941 published a total of 585 academic paper, its degree of academic specialization can be seen. At that time, the major domestic textile journals, such as Textile Times, Textile Weekly, and Friends of Textile, also published scientific papers, but they were not purely academic journals. The publication of Dyeing \& Weaving Weekly satisfies the desire of textile academia and industry for a platform for communication. The academic research achievements of scientific experts are known and utilized by the industry through this journal, and the problems of the industry are also discussed and exchanged through this journal. The journal aims to solve the practical technical problems in the field of textile at that time, and its contents lay emphasis on academic research, which greatly promoted the dissemination and development of textile technology. 


\subsection{Control the Communication Content and Guide the Research Direction}

Although the main function of the journal is as a platform for information exchange, the editorial group of Dyeing \& Textile Weekly is mostly made up of textile experts, who have been immersed in the industry for many years and have a great say in textile industry trends and textile science and technology. Therefore, the journal hopes to be more active in controlling the content and guiding the direction of research.

In addition to academic contents, the authors of other articles in Dyeing \& Textile Weekly are mostly editorial staff or scientific research personnel carrying the consciousness of the editorial department, with strong subjectivity. Most of the articles published in Dyeing \& Textile Weekly focus on the comments and discussions on the dynamics of the textile industry, which permeates the will of the editors. Among them, articles such as 'Talk of dismissal', 'from the north to the south of the textile mill selling tide', 'mercerization dyeing industry review' and other issues in the industry were analyzed, to explore solutions to the problems; Some articles, such as the relationship between industrial development and employment of women workers, the emphasis on rayon mills and textile mills, and a review of cotton goods marketing abroad, were based on the author's reflections on the development of China's textile industry. Articles such as Understanding of Dyeing, Weaving and Spinning Industry in the Extra Period, Denying Fine Domestic Goods, and Talking and Going focused on the national economic environment and put forward suggestions for the development of the textile industry, which also showed the authors' worries about the country and society.

Different from the general news reports, Dyeing \& Textiles Weekly has its own attitude and views on the developments and important news in the textile industry. In 1939, the magazine first reported the successful test of the improved 7-7 cotton spinning machine in Volume 4, Issue 5. The magazine believed that the improved 7-7 cotton spinning machine was carried out in the hand-spinning industry to increase rear production. It said that its invention was of great benefit to military and civilian clothes (Journal of Dyeing \& Textile, 1939). Later, in the 9th and 10th issues of the academic column in a continuous report on the improvement of the use of 7-7 cotton spinning machine (Mu, 1939; Mu, 1939). Similar reports in 1939, 4 (7) are visible, the journal published in news plate belt of a domestic hand improved successfully, the success of Ding Yaoquan improved hand strap to give a high evaluation. The magazine said, it is good news for domestic products, when foreign exchange is expensive and resources continue to flow out, if Ding's can go ahead and stem the flow, it will greatly benefit the operation of the factory (Journal of Dyeing, Weaving and Textile, 1939). Articles such as 'Cotton Industry Difficult to Resist' and 'Government and Relief', while reporting the latest developments in the textile industry, also express the concerns and opinions of the authors on the textile industry. Articles such as 'New Success in Silk Weaving Experiment' and 'New Invention by Lei Binglin' focus on the latest scientific research achievements in the field of textile, with a view to the prosperity of domestic goods. In addition, Dyeing \& Textiles Weekly also informs readers of the problems and the latest status of the textile industry through columns such as factory survey, appendix and monograph, so as to guide readers to reflect on and study the industry problems.

On December 15, 1940, the journal held an academic essay solicitation activity for the fifth anniversary of its establishment with the theme of 'how to train nurturance workers' and 'my career history'. The purpose of the authors is not just to celebrate the publication, but to explore the potential problems and crises of China's textile industry as a warning. With a limited number of textile experts in China, Dyeing \& Textile Weekly received 63 articles in half a month. The magazine concluded that the development of textile technology was hampered by a lack of time for training, a lack of normal recreational activities and a lack of attention paid to apprentice workers (Pan, 1941). Therefore, articles with profound views on industry issues are also selected and published in the essay selection.

The clear scientific standpoint makes the editorial group of the journal in the field of science and technology communication, from the publisher of information to the dissemination of the guide. The editor controls and guides the dissemination content and research direction of Dyeing \& Weaving Weekly, which is always aimed at improving the level of textile science and technology.

\subsection{Promote the Dissemination of Science and Technology and Promote the Development of the Industry}

The audience of professional sci-tech periodicals is limited to those who are engaged in their own business. Due to its position as an academic journal, Dyeing \& Weaving Weekly has raised the reading threshold. The audience group is only textile industry practitioners, including scientific experts, textile science students in colleges and universities, and technical personnel in various factories. Specialized and refined audiences did not affect Dyeing \& Textile Weekly, but promoted the dissemination and development of textile technology.

At the beginning of its establishment, Dyeing \& Weaving Weekly attracted great attention from the textile field, which objectively promoted the spread of textile science and technology. The journal was founded less than one 
year, most of the domestic dyeing and weaving factories became the audience of the journal, and other industries such as machine raw materials and dyes also subscribed to the journal (Zun, 1936). According to the statistics of Textile Construction Monthly, as of 1949, there were 5,075 textile factories and 238,368 textile workers in Shanghai alone (Textile Construction Monthly, 1949). Along with the development of Dyeing \& Weaving Weekly, a large number of textile practitioners make the publication have a wide audience base in the process of publication. It is worth mentioning that the magazine is not only published in China, but also received wide attention overseas. From 1935 to 1940, overseas sales of Dyeing \& Textiles Weekly accounted for 25\% of the magazine's total annual sales (Journal of Dyeing \& Textile, 1941). Wu Xiangyun, textile machinery department of Jardine Matheson, said that the magazine had a promising future and was a record in textile and dyeing (Zhu, 1941). The high popularity and wide distribution of the magazine expanded the spread of textile technology.

The Dyeing \& Weaving Weekly has consistently published and cared for the textile academia, which has promoted the development of the textile industry. During the seven years from 1935 to 1941, although the journal changed slightly in the section setting, and even added a lot of non-academic articles after 1941, the Dyeing \& Textiles Weekly did not change the scientific nature of its specialized academic, and always took textile academic as the focus of its publication.

In 1937, after the Shanghai Congress, all textile publications were forced to cease publication, and only Dyeing, Weaving and Textiles Weekly was adjusted to a monthly publication in the textile field, which was difficult to maintain (Zhu, 1941). After 1939, the textile academia gradually recovered its strength and prospered. Although periodicals have been reissued or new issues published. However, Dyeing \& Weaving Weekly, which persisted in publishing during the war, kept the textile academic journal from going out of print. After 1939, it still occupied an important position in the textile scientific and technological journal and became a well-known academic journal in the textile industry (Zhu, 1941).

From the above examples, we can see that the contribution of Dyeing \& Textile Weekly to the textile industry comes from its specialized and firm academic belief and the academic goal of the industry, which keeps the textile science and technology from stagnating. A large number of textile scientific research achievements are known to the outside world through the journal, which promotes the development of textile science and technology. Therefore, the journal is typical among modern textile science and technology periodicals, and becomes an important contribution of the journal in the dissemination of modern science and technology.

\section{Conclusions}

As a textile science and technology periodical with a long publishing time in modern times, Dyeing \& Textile Weekly was founded to boost the overall level of China's textile industry. It witnessed the development and innovation of modern textile science and technology. It is an important historical material for the study of modern textile science and technology, and has important value for the dissemination of modern science and technology.

From the perspective of science and technology communication, Dyeing \& Textile Weekly is committed to building the dual identity of communication platform and media. With the academic support and human resources of Shanghai Machine Dyeing and Weaving Association, the journal disseminate science and technology, and participate in guiding the research direction of textile science and technology. The group of its editors is an important scientific research force in the textile field. Therefore, the journal promotes the depth and breadth of textile academic research through the production and dissemination of textile academic achievements, which shows the important position of Dyeing \& Weaving Weekly in the textile field. It is precisely because of the innovative content and quality assurance of the articles published in academic research that Dyeing \& Textile Weekly can be continuously issued and widely spread, becoming a typical case among scientific and technological journals. Based on the present situation, in Dyeing \& Textile Weekly, we can clearly grasp the development state of modern textile science and technology, thus understanding the social orientation and responsibility of the current professional sci-tech periodicals, and providing reference for the dissemination and publication of modern sci-tech periodicals.

Admittedly, only examining Dyeing \& Textile Weekly can not reflect the whole picture of modern Chinese sci-tech periodicals, but as an important modern textile sci-tech periodical, the discussion on the way of running the journal and the dissemination of science and technology can also add a new dimension to the research of modern sci-tech periodicals. At the same time, it is hoped that the research of this journal can play a role in attracting more excellent research results on sci-tech journals and sci-tech communication in the academic circle. 


\section{References}

Friends of Textile. (1935). Expansion Plan of Textile Department of Nantong University. Friends of Textile, 4(5), 561-584.

Friends of Textile. (1937). The work of dyeing and chemical research institute is important. Friends of Textile, 6 , 448.

Gao, Q. (2019). Dyeing \& Weaving Weekly and Textile Industry before and after the Outbreak of the Total Anti-Japanese War. Donghua University, Shanghai, China.

Journal of Dyeing \& Textile. (1939). Message: 7-7 cotton spinning machine. Journal of Dyeing \& Textile, 4(5), 2128.

Journal of Dyeing \& Textile. (1941). Look at the five years of this magazine numerically. Journal of Dyeing \& Textile, 7(1), 2743.

Journal of Dyeing \& Textile. (1941). Friends of our journal. Journal of Dyeing \& Textile, 7(1), 2744-2746.

Journal of Dyeing, Weaving and Textile. (1939). Textile mill good news: domestic beater belt improvement success. Journal of Dyeing, Weaving and Textile, 4(7), 2164.

Journal of Dyeing, Woven and Textile Weekly. (1935). This notice. Journal of Dyeing, Woven and Textile Weekly, $1(1), 4$.

Liu, P. (2017). Research on Textile Times. Shanghai Normal University, Shanghai, China.

Mu, O. (1939). Simple Exposition of Improving 7-7 Cotton Spinning Machine (Continuing). Dyeing \& Textile Weekly, 4(10), 2205-2207.

Mu, O. (1939). Simple Instructions for Improving 7-7 Cotton Spinning Machine (to be continued). Dyeing \& Textile Weekly, 4(9), 2191-2192.

Nantong University textile science association, ED. (1934). The Textile Science Association of Nantong University. Jiangsu, DC: Nantong university textile science association (p.15).

Pan, Y., \& Zhu. S. (1941). Publication of solicitation papers. Journal of Dyeing \& Textiles, 7(1), 2813-2824.

Textile Construction Monthly. (1949). Shanghai factory statistics. Textile Construction Monthly, 2(5), 31.

Zhu, C. (1941). The Five Years of this Journal (I). Dyeing \& Weaving Weekly, 7(1), 2742-2742.

Zhu, W. (1935). Publications. Journal of Dyeing, Weaving and Textile, 1(1), 1-2.

Zun, S. (1936). A year of this magazine and our ideas. Dyeing \& Textile Weekly, 2(1), 837-838.

\section{Copyrights}

Copyright for this article is retained by the author(s), with first publication rights granted to the journal.

This is an open-access article distributed under the terms and conditions of the Creative Commons Attribution license (http://creativecommons.org/licenses/by/4.0/). 